\title{
MACHINABILITY EVALUATION OF CRYOGENICALLY TEMPERED DIE STEEL IN ELECTRIC DISCHARGE DRILLING
}

\author{
Shivnandan ${ }^{1}$, Simranpreet Singh Gill ${ }^{2}$ \\ ${ }^{1}$ Lecturer, Department of Mechanical Engineering, Government Polytechnic College, Amritsar -143104 (India) \\ ${ }^{2}$ Assistant Professor, Department of Mechanical Engineering, Beant College of Engineering and Technology, Gurdaspur- \\ 143521 (India), \\ shvnandan@gmail.com,ritchie_223@yahoo.com
}

\begin{abstract}
Electrical discharge drilling (EDD) is a well-known machining alternative for creating geometrically obscure shapes in die steel. Cryogenic temper of work and electrode material is innovative technology in the field of EDD. Work in hand investigates the effect of cryogenic tempering of AISI D2 steel (workpiece) and copper electrode (tool) on material removal rate (MRR) in EDD based on design of experiments approach. The discharge current, pulse-on-time and electrode-workpiece combination (cryogenically tempered or untempered) are the parameters selected for this study. The orthogonal array, signal-to-noise ratio (S/N) and analysis of variance (ANOVA) are used to find out the effect of cryogenic tempering on MRR. The results obtained demonstrate that the discharge current and pulse-on-time are the major parameters influencing the MRR for all samples, followed by electrode-workpiece combination i.e. cryogenic tempering of electrode and workpiece. Cryogenic tempering is found to have significant effect (nearly 10\%) on MRR. It is recommended to cryogenically temper both the electrode and workpiece to maximize the MRR.
\end{abstract}

Index Terms: Electric discharge drilling, Cryogenic tempering, Die steel, copper electrode

\section{INTRODUCTION}

Electrical discharge drilling (EDD) is a non-traditional technology of machining which has been extensively used to produce range of complex shaped dies and molds [1]. This process is based on removing material from a part by means of a series of repeated electrical discharges between tool called the electrode and the workpiece in the presence of a dielectric fluid [2]. In EDD, there is no direct contact between the electrode and the workpiece which eliminate mechanical stress, chatter and vibration problems during machining [1]. Only electrically conductive materials can be machined by EDD irrespective of its hardness [3]. AISI D2 die steel has a growing range of application in die and mould industries. EDD is extensively used to generate die cavities on AISI D2 steel.

Many researchers have worked on the EDD of AISI D2 and succeeded in improving the machining performance by using different innovative technologies. Guu and Hocheng [4, 5] studied the effects of machining parameters of rotary EDD of AISI D2 steel and found that material removal rate (MRR) and surface finish increases with the increase in rotation speed. However, the application of orbiting of the electrode or workpiece is limited only to round shape cavities. Another promising MRR improvement technique includes the modification in electrode metallurgy and replacing the traditional dielectric fluids with novel fluids. Medellin et al. [6] presented an investigation of the EDD performance on
AISI D2 tool steel using water as the dielectric. They proved that the greatest performance, which corresponds to the maximum MRR and the minimum tool wear rate (TWR), is achieved with a mixture of 75 per cent tap water and 25 per cent deionized water as the dielectric. Kumar and Batra [7] investigated the response of three die steel materials including AISI D2 steel to surface modification by EDD with tungsten powder mixed in the dielectric medium and reported more than $100 \%$ in micro-hardness for all the three die steels. Kansal et al. [8] studied the effect of silicon powder mixing into the dielectric fluid of EDD on machining characteristics of AISI D2 die steel and reported that suspension of silicon powder into the dielectric fluid of EDM appreciably enhanced MRR. Hamid and Lajis [9] did experiments on EDD of AISI D2 hardened steel in kerosene with a copper tungsten (Cu35\% - W65\%) tool electrode and reported relatively higher MRR. Prabhu and Vinayagam [10] investigated the machining characteristics of AISI D2 tool steel with copper as a tool electrode and multi wall carbon nano-tubes mixed with dielectric fluids in EDD process to analyze the surface roughness. They reported nearly $34 \%$ improvement in surface finish by using carbon nano tube mixed dielectric fluid. Cryogenic tempering is another novel technique which can be used in EDD for improving the machining performance. Cryogenic tempering of electrode and/or workpiece can have significant positive effects on machining of AISI D2 steel by EDD [11, 12]. Gill and Singh [13] investigated electric discharge drilling (EDD) of deep cryogenically treated $\mathrm{Ti}$ 
6246 alloy and revealed the improvements in MRR, wear ratio (WR) and TWR. From the review of literature, it is clear that effects of cryogenic tempering on EDD have not yet been investigated extensively. Hence, the present study has been planned to investigate the effect of cryogenic tempering of AISI D2 steel (workpiece) and copper electrode (tool) on MRR of AISI D2 steel in EDD based on Taguchi's method.

\section{EXPERIMENTAL SETUP}

\subsection{Work/Tool and Cryogenic Tempering Cycle}

Commercially available AISI D2 steel in annealed form having average hardness of $17 \mathrm{HRC}$ was used in the shape of rectangular block. AISI D2 steel workpiece was heat treated to hardness of $60 \mathrm{HRC}$ which is required for most of the applications which it address [14]. After heat treatment the workpiece was cut in small pieces of dimension $25 \mathrm{~mm} \times 25$ $\mathrm{mm} \times 10 \mathrm{~mm}$ and these pieces were used for EDD experiments. Pure copper was used as the electrode material because of its high electrical and thermal conductivity. The electrode tip diameter was taken as $7 \mathrm{~mm}$.

All the workpiece and electrode samples were classified in two different groups as untempered with no extra treatment and cryogenically tempered. Fig. 1 shows the cryogenic tempering cycle used to treat the specimens.

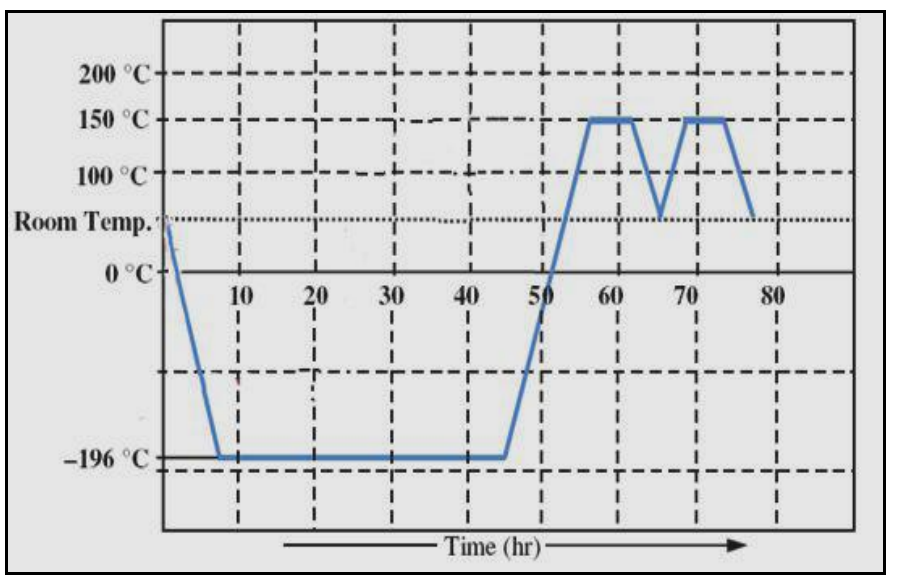

Fig-1: Cryogenic tempering cycle

\subsection{Design of Experiments}

A standard Taguchi experimental plan with L9 (33) array was chosen for the statistical analysis. In Taguchi's design method, the experimental results are transformed into a signal-to noise $(\mathrm{S} / \mathrm{N})$ ratio. In this study, Taguchi's the higher-the-better performance characteristic was considered for MRR, a property which is generally expected to be as high as possible. The S/N ratio was computed for each level of process parameters. Additionally, analysis of variance (ANOVA) was performed to verify which parameters were statistically significant. Then, the optimal combination of the test parameters was determined. The control factors (parameters), their codes and levels are given in Table 1. Table 2 gives the experimental design using L9 orthogonal array and obtained results.

Table-1: Control factors and their levels

\begin{tabular}{|l|l|l|l|l|l|}
\hline Cod & Control Factor & \multirow{2}{*}{$\begin{array}{l}\text { Uni } \\
\text { ts }\end{array}$} & & \multicolumn{3}{|l|}{ Level } \\
\cline { 4 - 6 } & & 1 & 2 & 3 \\
\hline $\mathrm{A}$ & $\begin{array}{l}\text { Discharge current } \\
\text { Ifp) }\end{array}$ & $\mathrm{A}$ & 3 & 6 & 9 \\
\hline $\mathrm{B}$ & $\begin{array}{l}\text { Pulse-on-time } \\
\text { (Ton) }\end{array}$ & $\mu \mathrm{s}$ & 100 & 300 & 500 \\
\hline $\mathrm{C}$ & $\begin{array}{l}\text { Electrode } \\
\text { workpiece } \\
\text { combination }\end{array}$ & $\mathrm{NA}$ & $\begin{array}{l}\text { UTE+ } \\
\text { CTW }\end{array}$ & $\begin{array}{l}\text { CTE+ } \\
\text { UTW }\end{array}$ & $\begin{array}{l}\text { CTE+ } \\
\text { CTW }\end{array}$ \\
\hline
\end{tabular}

UTE-untempered electrode; CTW-cryogenically tempered workpiece; CTE- cryogenically tempered electrode; UTWuntempered workpiece

Table-2: Experimental design using L9 orthogonal array.

\begin{tabular}{|l|l|l|l|l|l|}
\hline $\begin{array}{l}\text { Experiment } \\
\text { Number }\end{array}$ & $\mathrm{A}$ & $\mathrm{B}$ & $\mathrm{C}$ & \multicolumn{2}{|l|}{ MRR (mg/min) } \\
\cline { 4 - 6 } & & & & Result & $\begin{array}{l}\text { S/N } \\
\text { Ratio }\end{array}$ \\
\hline 1 & 3 & 100 & 1 & 7.1 & 17.02 \\
\hline 2 & 3 & 300 & 2 & 7.6 & 17.61 \\
\hline 3 & 3 & 500 & 3 & 8.0 & 18.05 \\
\hline 4 & 6 & 100 & 2 & 8.1 & 18.16 \\
\hline 5 & 6 & 300 & 3 & 8.2 & 18.32 \\
\hline 6 & 6 & 500 & 1 & 8.2 & 18.27 \\
\hline 7 & 9 & 100 & 3 & 8.4 & 18.48 \\
\hline 8 & 9 & 300 & 1 & 8.2 & 18.25 \\
\hline 9 & 9 & 500 & 2 & 8.6 & 18.68 \\
\hline
\end{tabular}

EDD experiments were carried out on $\mathrm{CNC}$ machine. In all the experiments, kerosene oil was used as dielectric medium. The machining time was kept $20 \mathrm{~min}$ for all the experiments. Since, the present study was planned to evaluate the effects of cryogenic tempering, the electrode-workpiece combination was also considered as one of the controllable parameters in addition to discharge current and pulse-on-time to facilitate the experimental work. The experiments were conducted keeping the considered factors at three levels. The range of each factor has been selected by performing preliminary experiments and based on the capability of the machine. The machining experiments were carried out to analyze the influence of testing parameters on MRR by fixing the duty cycle of 0.56 and gap voltage of $60 \mathrm{~V}$. MRR has been defined as the ratio of the wear weight of workpiece to machining time $[15,16]$. 


\section{RESULTS AND DISCUSSIONS}

One of the most common methods of evaluating machining performance in the EDD operation is MRR as performance characteristics. Hence, proper selection of the machining parameters ensures better response which here is higher MRR. Analysis of the influence of each control parameter (A, B, and C) on the MRR was performed with signal-to-noise $(\mathrm{S} / \mathrm{N})$ response table. Table 2 shows the orthogonal array and associated experimental results for MRR with calculated $\mathrm{S} / \mathrm{N}$ ratios. The $\mathrm{S} / \mathrm{N}$ response table and means response table for MRR is presented in Table 3 and 4 respectively. These tables show the calculated $\mathrm{S} / \mathrm{N}$ ratios and mean for each level of control factors. The control factor that has the strongest influence is determined depending on the value of $\Delta$ (delta) as shown in Table 3 and 4. Delta equals the difference between maximum and minimum $\mathrm{S} / \mathrm{N}$ ratios for a particular control factor. The higher the value of delta, the more influential is the control factor. It can be seen in Tables 3 and 4 that the strongest influence was exerted by the discharge current (factor A) followed by pulse-on-time (factor B) and electrodeworkpiece combination (factor $\mathrm{C}$ ). The plots for $\mathrm{S} / \mathrm{N}$ ratios and means are shown in Fig. 2. The optimal levels for each control factor can be easily determined from these graphs by considering the highest points in accordance with Taguchi's "the higher the better" performance characteristic.

Table-3: S/N response table for MRR (larger is better).

\begin{tabular}{|c|c|c|c|}
\hline Level & A & B & C \\
\hline 1 & 17.56 & 17.89 & 17.85 \\
\hline 2 & 18.26 & 18.06 & 18.16 \\
\hline 3 & 18.48 & 18.34 & 18.29 \\
\hline$\Delta$ & 0.91 & 0.45 & 0.44 \\
\hline Rank & 1 & 2 & 3 \\
\hline
\end{tabular}

Table-4: Mean response table for MRR.

\begin{tabular}{|c|c|c|c|}
\hline Level & A & B & C \\
\hline 1 & 7.56 & 7.86 & 7.83 \\
\hline 2 & 8.18 & 8.01 & 8.10 \\
\hline 3 & 8.40 & 8.26 & 8.21 \\
\hline$\Delta$ & 0.83 & 0.40 & 0.38 \\
\hline Rank & 1 & 2 & 3 \\
\hline
\end{tabular}

Response graphs (Fig. 2.) show the variation of $\mathrm{S} / \mathrm{N}$ ratio when the setting of the control factors is changed from one level to another. Based on mean and $\mathrm{S} / \mathrm{N}$ ratio values the optimal level setting of the respective control factors is A3B3C3. This implies that in order to enhance the MRR, the discharge current and pulse-on-time should be increased and both electrode and workpiece should be cryogenically tempered (level 3 of factor C; Table 1).

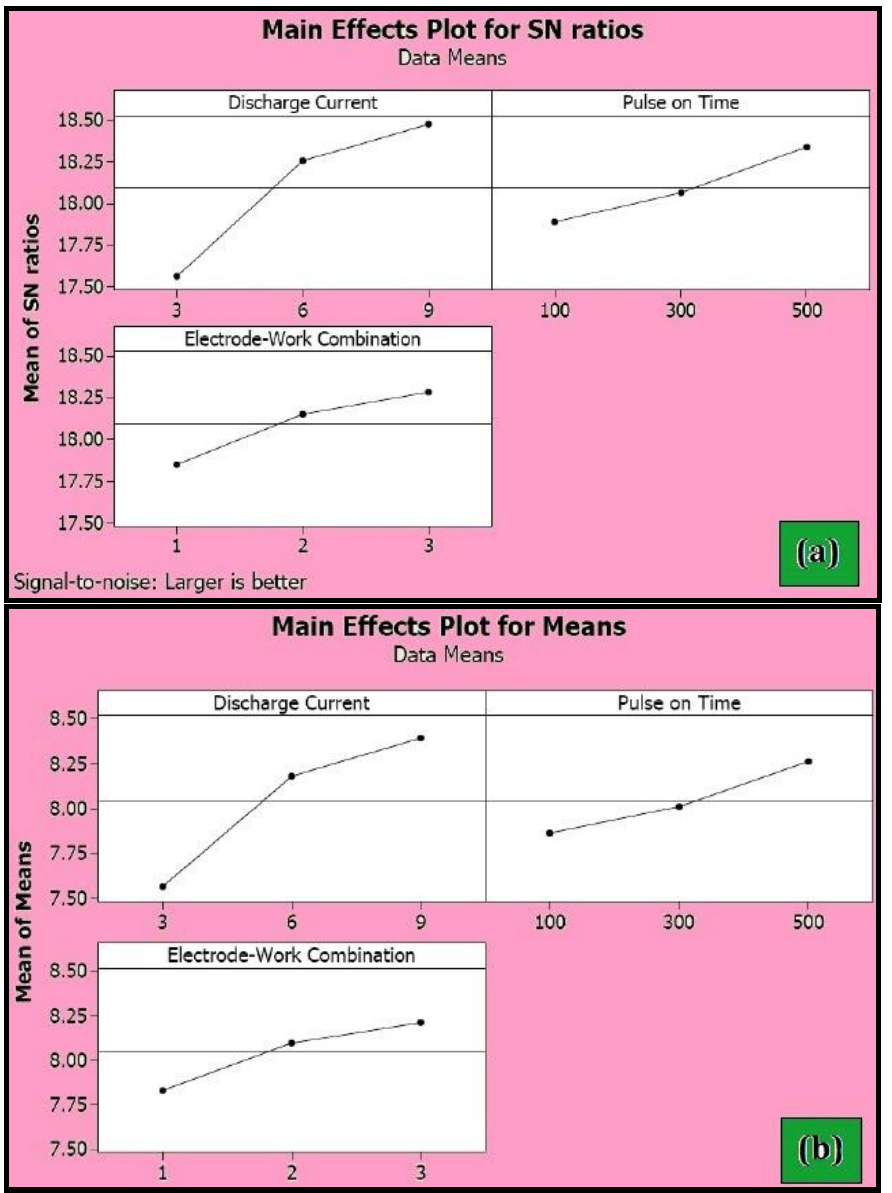

Fig-2: Plots for MRR: (a) S/N ratio and (b) mean.

Also, it is evident from Fig. 2 that enhancement in MRR (in comparison to level 1 of factor C; Table 1) can also be obtained by cryogenically tempering electrode only (level 2 of factor C; Table 1), however in this case marginal reduction in MRR was noted when compared with MRR obtained by using cryogenically tempered both electrode and workpiece (level 3 of factor C; Table 1). Hence, it is recommended to cryogenically temper both the electrode and workpiece to optimize the MRR.

It is very interesting to note that irrespective to the type of workpiece (cryogenically tempered or untempered) used, the MRR increased while machining with cryogenically tempered electrode. Hence, it can be concluded that both cryogenically tempered electrode and workpiece has their respective role to play in enhancing the MRR and their coupled effect results in additional improvement in MRR. The fact that cryogenic tempering of AISI D2 steel increases its hardness is very well documented in published research [11, 12, 17-26]. In present study also, the average hardness value of cryogenically tempered AISI D2 steel was checked and found out to be $63 \mathrm{HRC}$ which is $3 \mathrm{HRC}(5 \%)$ more than the untempered sample. The other major change in metallurgy of AISI D2 steel after cryogenic tempering is transformation of relatively 
soft retained austenite into harder martensite [11, 12, 17-26]. Hence, the improvement in hardness of the cryogenically tempered AISI D2 steel to the untempered ones is attributed to the near absence of retained austenite and more homogeneous distribution of a larger number of finer secondary carbides in the former specimens. It is thought that this change in hardness of AISI D2 steel after cryogenic tempering may have positive effect as far as increase in MRR is concerned. Nadig et al. [27] observed significant enhancement of thermal conductivity values after cryogenic tempering of OFHC copper samples. Hence from the survey of literature, it is clear that cryogenic tempering has ability to improve the thermal conductivity of the copper and its alloys. It can be concluded that increased conductivity of copper electrode after cryogenic tempering might have caused more efficient heat transfer away from the electrode tip during machining.

The ANOVA was used to investigate which design parameters significantly affect the quality characteristic. The ANOVA is performed by separating the total variability of the $\mathrm{S} / \mathrm{N}$ ratios into contributions by each of the design parameters and the errors. The total variability of $\mathrm{S} / \mathrm{N}$ ratio is measured by the sum of the squared deviations from the total mean $\mathrm{S} / \mathrm{N}$ ratio. Examination of the calculated Fisher's values (F) for all control factors also shows a very high influence of discharge current (factor A) and low influence of pulse-on-time (factor B) and electrode - workpiece combination (factor C) on MRR of AISI D2 steel (Table 5). The last column of the Table 5 indicates the percentage of contribution $(\mathrm{P})$ of each factor, thus exhibiting the level of influence on the MRR. The table shows that the discharge current, pulse-on-time and electrodeworkpiece combination have percentage contributions of 59\%, $11 \%$, and $10 \%$ in the MRR of AISI D2 steel respectively.

Table-2: Experimental design using L9 orthogonal array.

\begin{tabular}{|l|c|c|c|c|c|}
\hline \multicolumn{1}{|c|}{ Source } & DoF & $\begin{array}{c}\text { Seq } \\
\text { SS }\end{array}$ & $\begin{array}{c}\text { Adj } \\
\text { MS }\end{array}$ & F & P (\%) \\
\hline Discharge current & 2 & 2.24 & 1.12 & 26.0 & 59 \\
\hline Pulse on time & 2 & 0.49 & 0.24 & 05.6 & 11 \\
\hline $\begin{array}{l}\text { Electrode-Work } \\
\text { Combination }\end{array}$ & 2 & 0.46 & 0.23 & 05.3 & 10 \\
\hline Residual Error & 11 & 0.47 & 0.04 & & \\
\hline Total & 17 & 3.67 & & & \\
\hline
\end{tabular}

\section{CONCLUSIONS}

The Taguchi method was applied to investigate the effects of cryogenic tempering on material removal rate of AISI D2 steel by electric discharge drilling using copper electrode. Although the discharge current (59\% contribution) and pulse-on-time (11\% contribution) are the two most significant process variables effecting MRR of AISI D2 steel with copper electrode, cryogenic tempering is also significantly effective in increasing the material removal rate with nearly $10 \%$ contribution. Cryogenic tempering increases the hardness of
AISI D2 steel and electrical/thermal conductivity of copper electrode which ultimately helps in increasing the material removal rate.

\section{REFERENCES}

[1] Ho KH, Newman ST. State of the art electrical discharge machining (EDM). Int $\mathbf{J}$ Mach Tool Manu 2003; 43: 1287-1300.

[2] Luis CJ, Puertas I, Villa G. Material removal rate and electrode wear study on the EDM of silicon carbide. J Mater Process Technol 2005; 164-165: 889-96.

[3] Ramasawmy H, Blunt L. Effect of EDM process parameters on 3D surface topography, J Mater Process Technol 2004; 148: 155-64.

[4] Guu Y, Hocheng H. High cycle fatigue of electricaldischarge machined AISI D2 tool steel. Int J Mater Prod Tec 2001; 16 (6-7): 642-57.

[5] Guu Y, Hocheng H. Effects of workpiece rotation on machinability during electrical-discharge machining. Mater Manuf Process 2001; 16 (1): 91-101.

[6] Medellin HI, de Lange DF, Morales J, Flores A. Experimental study on electrodischarge machining in water of D2 tool steel using two different electrode materials. P I Mech Eng B-J Eng 2009; 223 (11): 142330.

[7] Kumara S, Batra U. Surface modification of die steel materials by EDM method using tungsten powdermixed dielectric. J Manu Process 2012; 14: 35-40.

[8] Kansal HK, Singh S, Kumar P. Effect of silicon powder mixed EDM on machining rate of AISI D2 die steel. J Manu Processes 2007; 9 (1): 13-22.

[9] Hamid FEA, Lajis MA. High performance in EDM machining of AISI D2 hardened steel. Adv Mater Res 2012; 500: 259-65.

[10] Prabhu S, Vinayagam BK. Analysis of surface characteristics of AISI D2 tool steel material using electric discharge machining process with single-wall carbon nanotubes. Int J Machining Machinability Mater 2011; 10(1/2): 99 - 119.

[11] Gill SS, Singh J, Singh R, Singh H. Metallurgical principles of cryogenically treated tool steels - a review on the current state of science. Int J Adv Manuf Tech 2011; 54 (1-4): 59-82.

[12] Gill SS, Singh H, Singh R, Singh J. Cryoprocessing of cutting tool materials - a review. Int J Adv Manuf Tech 2010; 48 (1-4): 75-92.

[13] Gill SS, Singh J. Effect of deep cryogenic treatment on machinability of titanium alloy (Ti-6246) in electric discharge drilling. Mater Manuf Process 2010; 25 (6): 378-85.

[14] Budinski KG. Engineering materials, properties and selection. New Jersey: Prentice Hall; 1992; p. 373-411.

[15] Patel KM, Pandey PM, Rao PV. Study on machinabilty of $\mathrm{Al} 2 \mathrm{O} 3$ ceramic com-posite in EDM using response surface methodology. J Eng Mater-T ASME 2011; 133(2), 021004-1-021004-10. 
[16] Abdulkareem S, Khan AA, Konneh M. Reducing electrode wear ratio using cryogenic cooling during electrical discharge machining. Int $\mathbf{J}$ Adv Manuf Tech 2009; 45:1146-51.

[17] Yang HS, Wang J, Shen BL, Liu HH, Gao SJ, Huang SJ. Effect of cryogenic treatment on the matrix structure and abrasion resistance of white cast iron subjected to destabilization treatment. Wear 2006; 261: 1150-154.

[18] Das D, Dutta AK, Toppo V, Ray KK. The Effect of cryogenic treatment on the carbide precipitation and tribological behavior of D2 steel, Mater Manuf Process 2007; 22: 474-80.

[19] Molinari A, Pellizzari M, Gialanella S, Straffelini G, Stiasny KH. Effect of deep cryogenic treatment on the mechanical properties of tool steels. J Mater Proc Tech 2001; 118: 350-55.

[20] Collins DN, Dormer J. Deep cryogenic treatment of D2 cold-worked tool steel, Heat Treat Met 1997; 3:71-74.

[21] Wierszyllowski I. The influence of post-quenching deep cryogenic treatment on tempering processes and properties of D2 tool steel: studies of structure, XRD, dilatometry, hardness and fracture toughness. Defect Diff Forum 2006; 258-260: 415-20.

[22] Moore KE, Collins DN. Cryogenic treatment of three heat treated tool steels. Key Eng Mater 1993; 86-87: 47-54.

[23] Zhirafar S, Rezaeian A, Pugh M. Effect of cryogenic treatment on the mechanical properties of 4340 steel. J Mater Proc Tech 2007; 186: 298-303.

[24] Kalin M, Leskov`sek V, Vǐzintin J. Wear behavior of deep-cryogenic treated highspeed steels at different loads. Mater Manuf Process 2006; 21: 741-46.

[25] Liu HH, Wang J, Shen BL, Yang HS, Gao SJ, Huang SJ. Effects of deep cryogenic treatment on property of 3Cr13Mo1V1.5 high chromium cast iron. Mater Des 2007; 28: 1059-064.

[26] Cohen P, Kamody D. Cryogenics goes deeper. Cutting Tool Eng 1998; 50: 46-50.

[27] Nadig DS, Ramakrishnan V, Sampathkumaran P, Prashanth CS. Effect of cryogenic treatment on thermal conductivity properties of copper. Advances In Cryogenic Engineering: Transactions of the International Cryogenic Materials Conference - ICMC, Volume 58. AIP Conference Proceedings, Volume 1435, pp. 133-139 (2012).

\section{ACKNOWLEDGMENTS}

The work presented in this paper is the outcome of thesis done by the first author during Master of Technology (Production Engineering) Degree under the guidance of second author. The authors are thankful to faculty and staff of Beant College of Engineering and Technology, Gurdaspur (India) for support and encouragement.

\section{BIOGRAPHIES}

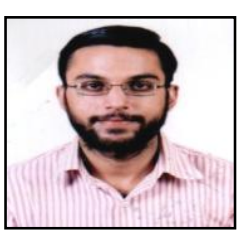

Shivnandan is currently working as Lecturer in Department of Mechanical Engineering at Government Polytechnic College Amritsar (India). After completing his B.Tech in Mechanical Engineering, currently he is doing M.Tech at Beant College of Engineering and Technology, Gurdaspur (India).

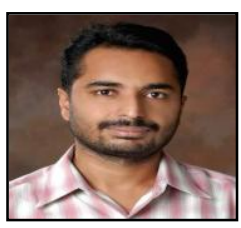

Shivnandan is currently working as Lecturer in Department of Mechanical Engineering at Government Polytechnic College Amritsar (India). After completing his B.Tech in Mechanical Engineering, currently he is doing M.Tech at Beant College of Engineering and Technology, Gurdaspur (India). 